\title{
A Redefinição democrática através da praxis Intencional: a conscientização dos valores éticos
}

\author{
Ivanilse Leite Miranda*
}

\section{RESUMO}

Procurando-se reafirmar a importância da teoria marxista, este artigo propõe-se a redefiniçăo da democracia enquanto método e a possibilidade de sua superação para democracia-condição social através da praxis intencional exercida no cotidiano. A compreensão da vida cotidiana requer a sua reconstituição ontológica pela via da conscientização dos valores éticos contidos na genericidade.

\section{NOTAS INTRODUTÓRIAS}

1994 caracteriza-se como mais um ano de complexidades e incertezas. Contudo, o que importa é que à medida que o ambiente se torna mais instável devido a mudanças estruturais e conjunturais, torna-se fundamental, como ponto de partida, não se perder de vista a concepção da liberdade humana entendida como necessidade reconhecida.

Há otimismo num mundo de desesperanças. Se nas últimas décadas, éramos então os promulgadores das críticas ferozes incontestes ao sistema em geral e à ciência em particular - voltados para um mundo "em si" - hoje, adidos num trabalho coletivo inter e intra disciplinar, só nos resta uma alternativa: a de rever caminhos, a de rever valores, a de ir em busca de novas soluçðes.

A compreensão das mudanças profundas que abrangem as esferas heterogêneas da vida social, a revogação da alienação, a superação da discrepância entre 0 desenvolvimento do gênero humano e do particular e a participação consciente na realização de sua essência garantiriam, pelo menos em tese, sua superação. Novos problemas são formulados e obviamente, deverão ser enfrentados com novas soluçð̃es.

Neste contexto de crise e de reordenamento ou desordenamento mundial, vivemos no Brasil uma situação contraditória e paradoxal. O paradoxo é, de fato, aparente - mas está inscrito na realidade da nossa sociedade. A possibilidade efetiva da cidadania operar como legitimadora da ordem burguesa é atestada, pelo esforço de vários "partidos" políticos para criar um novo campo de polarização social.

"Profa. Assistente Doutor do Depto. de Psicologia da Educação da Faculdade de Ciências e Letras da UNESP - Campus de Araraquara. 
Entretanto, nessas condiçð̃es, o que se deve questionar, particularmente, é a possibilidade de uma ordem não autocrática, permeável à democratização da sociedade e do Estado.

Não se pode mais esperar por um dia mítico "DIA M" da tomada do poder político pelo proletariado aliado a outras classes. Por certo "os homens fazem sua própria história, mas não a fazem como querem; não a fazem sob circunstâncias de sua escolha e sim sob aquelas com que se defrontam diretamente, legadas e transmitidas pelo passado", eis uma realidade. (Marx,1984,p.69).

Vivemos a desagregação de Naçð̃es e como decorrência, há a volta de ressentimentos, de regionalismos, de provincianismos. Afinal, nem os projetos do capitalismo e socialismo Nacionais vingaram. Há e houve equívocos. Refletir e reconhecer o processo significa caminhar, ir-se em direção a novas perspectivas. Há desafios teóricos e práticos que devem ser assumidos, e mais, os paradigmas estão sendo postos em questão.

\section{A RACIONALIDADE FLEXÍVEL: UM POSSÍVEL CAMINHO NA E PARA A CONQUISTA DEMOCRÁTICA.}

Há alguns anos, as Ciências Humanas têm sido o campo das mais veementes discussões sobre a crise dos paradigmas. Cientistas passaram a duvidar da capacidade explicativa dos clássicos utilizados como válidos. Kuhn (1990) tornou-se moda nas discussðes.

Hoje, inicia-se um movimento semelhante nas outras áreas do conhecimento. Isto coloca em discussão todos os fundamentos da Ciência, principalmente os cartesianos. Com esta preocupação, um possível caminho é o da redefinição cujo ponto de partida poder-se-ia encontrar nas teorias clássicas. É este o nosso caminho.

Como bem sintetizou José Paulo Netto em seu artigo “Teoria e Revolução em Marx ", ao contrário do que querem as boas almas, que substituem a reflexão crítica pela postura mística, o legado de Marx é o oposto de um ato de fé: antes, é um complexo de hipóteses e soluçðes sempre a verificar.

O que se descortina é a compreensão da socialidade a partir dela mesma, historicamente posta e determinada, com todas as implicaçðes de avanço e recuo, trazendo em si a interdição desta possibilidade posta pela reificação.

Ao mesmo tempo se inaugura uma inteligibilidade do social (enquanto síntese da história, da economia e da cultura) referida à sua imanência e nutrida pelo tratamento da sua realidade entendida como totalidade dinâmica e auto-estruturada.(Netto, 1990,p.61-68).

Trata-se de promover a generalização e a universalização dos institutos cívicos, 
ainda no marco do ordenamento capitalista, simultaneamente à ampliação de seu conteúdo.

Para o início das reflexð̃es cabe lembrar que em " $O 18$ Brumário de Luis Bonaparte", Marx já antecipa que "o principiante que aprende um novo idioma traduz sempre as palavras deste idioma para sua língua natal; mas, só quando puder manejálo sem apelar para o passado e esquecer sua própria língua no emprego da nova, terá assimilado o espírito desta última e poderá produzir livremente nela"'(Marx,1984,p.70).

O que se pð̃e em questão é a redefinição da democracia: seus parâmetros não se esgotam no conjunto dos direitos cívicos tradicionais, mas situam-se no patamar de uma participação social alargada que se explicita em todos os espaços da socialidade.

Agnes Heller atenta para o fato de que "é justo medir as estruturas sociais aplicando-lhes como critério suas próprias possibilidades ontológicas" (Heller,1985,p.11).

Para se converter a possibilidade da teoria social de Marx em realidade é necessário superar a reificação posta secularmente no fetichismo da mercadoria. "A propriedade privada tornou-nos tão estúpidos e unilaterais que um objeto só é nosso quando o temos, quando existe para nós como capital ou quando imediatamente possuído, comido, bebido, habitado, em resumo, utilizado por nós".(Marx:apud Silveira:1989,p.48)

No sentido marxista destas noçð̃es há ruptura, há disjunção, há contradição entre a essência e a existência humana. Para nós, há uma possível diretriz: conhecendo-se conscientemente a alienação e seus perigos, é necessário combatê-la. Se ela é um fato, urge investigá-la e superá-la. Tal concepção nos aponta e nos alerta para um princípio: o dever de não estarmos satisfeitos jamais.

Neste ordenamento o pensamento de Gramsci explicita "que existam as possibilidades objetivas de nao se morrer de fome e que, mesmo assim, se morra de fome, é algo importante, ao que parece. Mas a existência das condiçð̃es objetivas - ou possibilidades, ou liberdade - ainda não é suficiente: é necessário conhecê-las e saber utilizá-las"'(Gramsci, 1978,p.47).

Identificamos a história com a atividade consciente do homem. Assinalamos uma perspectiva do homem ativo que cria e age no quadro das relaçðes concretas; age conscientemente, fazendo suas escolhas entre várias possibilidades.

A atividade humana, por um lado encontra-se condicionada socialmente (em relação aos interesses de classe). Por outro lado, nas bases dos processos objetivos fica a escolha humana (individual), mas não imposta. A atividade quando baseada numa relação consciente lhe confere o título de livre escolha. Como decorrência é o homem criador da História, não como mônada de livre vontade por nada condicionada, mas 
como um produto histórico.

Isto posto, claro está que o processo de conhecimento, a relação entre o sujeito que conhece e a realidade objetiva a ser conhecida, contém em si o seu limite: a subjetividade.

Esta é a parcialidade e limitação intencional que assumimos. Com o aporte marxista, pensaremos, como tal no curso das reflexões, mas não no sentido de busca a respostas numa perspectiva ortodoxa. Isto porque a filosofia marxiana "não apresenta um corpo acabado de categorias ao qual se deve subordinar de forma absoluta a realidade. Pelo contrário, seu corpo teórico expõe os avanços do pensamento, oferecendo generalizações teóricas e metodológicas que aproximam as ciências particulares a seu objeto de estudo '(González, 1985,p.16-17).

Expurga-se neste enfoque a conversão mecânica das ciências particularesà teoria marxiana, reduzindo-as mecanicamente. Isto não quer dizer, de forma alguma, que se coloca a ruptura da inevitável relação dialética que opera entre a filosofia marxista e as ciências particulares. A primeira, servindo de base e fundamento, recebe os descobrimentos das outras que vão garantir a mobilidade, o desenvolvimento, o aperfeiçoamento do marxismo: sua historicidade e contemporaneidade.

Coloca-se o compromisso real e efetivo, teórico, metodológico, prático e ideológico com o marxismo-filosofia que expressa em sua unidade cpistêmica, sua ontologia, seu valor de guia reflexivo para as ciências em particular, e não colocá-las a serviço da teoria de Marx. Desconhecer isso seria abrir as portas para o dogmatismo pseudo científico, afinal, o marxismo é unidade na diversidade.

O conhecimento e o saber do singular têm um preço: assumir o ponto de vista do conhecimento implica assumir-se também o ponto de vista da transformação. É nisso que a contribuição específica do marxismo nos parece, mais que nunca, insubstituivel.

É crível explicitar-se, por um lado, que o conhecimento humano é cumulativo, que se desenvolve no tempo e espaço históricos em que se forja. Por outro lado, esse desenvolvimento é acompanhado por uma mudança das verdades relativas formuladas como resultado desse conhecimento.

Entende esta acepção que o objeto do conhecimento é infinito, quer se trate do objeto considerado como a totalidade do real ou do objeto percebido como um qualquer dos seus fragmentos e aspectos. Totalidade e fragmentos são infinitos na medida em que é infinita a quantidade de correlações e mutações no tempo referido a um determinado momento histórico.

Desse modo o conhecimento a ser produzido basear-se-á sempre nas verdades parciais, tomando-as como ponto de partida para um novo desenvolvimento; $\mathrm{e}$, ora alargando-as, ora limitando-as, ora superando-as, subjaz o processo infinito do conhecimento.

Esta assertiva considera que o sujeito nunca é um elemento passivo no conheci- 
mento, masque desempenhaum papel ativo; introduz sempre seu "aporte " referenciado por sua perspectiva de mundo, isto é, pelo seu condicionamento social.

No que se refere à problemática que poder-se-ia enfrentar no binômio ciência e ideologias, compreende-se que entre estas oposiçðes e proposiçðes teóricas muitas vezes divergentes, há também um suporte, qual seja, de identidade. Em outras palavras, na oposição, na diversidade há unidade.

Para Chauí," o presente é histórico porque é o repertório do passado e percepção do possível(...) em cada presente, a síntese do passado e o prenúncio do possível transformam as condiçð̃es da tomada de consciência e a empurram para uma prática mais abrangente"'(Chaui, 1989,p.185).

Embora a acumulação de verdades relativas porte em si um condicionamento social que a limita, a superação destas restriçð̃es poder-se-á efetivar na medida em que haja consciência destes limites, desse processo e de suas eventuais deformaçðes.

E nada é mais difícil do que se fazer respeitar as regras do jogo democrático, onde as Instituiçðes de controle, consubstanciadas e legitimadas na sociedade capitalista produzem e dirigem por pura coerção as práticas democráticas. Não é preciso aduzir, a esta altura, que uma redefinição prática da democracia resulta do direcionamento consciente da maioria.

Para nós, a especificidade cicntífica contributiva à democracia, tem como enfoque orientador de seu percurso a conscientização dos indivíduos com relação aos fatores presentes na totalidade, o que leva à construção de novas variáveis.

O marxismo enquanto pensamento materialista e histórico, traz no seu alcance ético a constante preocupação de desalojar os fetichismos para melhor decifrar o sentido dos atos humanos contra as alienaçðes dominantes. Liberar, na prática, as vias de uma representação subjetiva da história por aqueles que são seus atores. Esta dimensão marxiana considera num plano mais abrangente, mas não menos importante, a dimensão ontológica. Aqui o trabalho alienado - ainda sob as condiçðes do capital aliena do homem: a natureza e a si mesmo, isto é " aliena do homem o gênero"'(Marx, 1968,p,155).

Compreende-se que a fonte da tolerância em seu sentido mais amplo reside na reflexão consciente. Para atuar-se efetivamente na execução de projetos multidisciplinares, esta tolerância, que atua igualmente sobre o fenômeno observado, nos incita a admitir que é falso e perigoso pensar que as escolas de pensamento se dividem estritamente, uma levando unicamente à verdade e as outras ao erro.

Pelo contrário, esta proposta incide em trabalhar com o conceito de totalidade. Totalidade entendida como captação social e individual, o desfeitiche, a explicação, as alternativas possíveis, a reuniåo de forças necessárias para humanizar. Este, éum entre outros caminhos possiveis para chegar-se à democratização.

Desse modo deve-se levar em conta que o conhecimento é limitado, de uma ou

Paidéia, FFCLRP-USP. Rib. Preto, 7, Agosto/1994. 
de outra maneira deformado, e que nosso possivel "adversário" pode também possuir uma parte da razão.

No fazer científico, o ponto de convergência genérico é a humanização do homem, do refinamento de suas faculdades no salto ontológico dos valores contidos na genericidade. Considerando-se o princípio de tolerância e de coerência científica teórica multidisciplinares, deixa-se de lado o fanatismo, o preconceito, a fragmentação - em beneficio da tolerância frente à diversificação do conhecimento - livra-se da dominação de uma só perspectiva cognitiva e suas restriçðes.

Não estamos propondo nenhum ecletismo, mas a liberdade de escolha entre alternativas possíveis. Isto constitui uma garantia do processo de conhecimento e sua viabilidade possivel neste momento histórico. Conhecendo os condicionamentos possiveis, poder-se-á, pelo menos em tese, superá-los. O fazer científico corresponde à possibilidade real do momento histórico em que se forja e desenvolve, e é neste sentido que a classe de fatos que a ciência revela a natureza das coisas.(Kuhn,1990,p.46).

Com Kunh, compreendemos que uma abordagem ampla da ciência é a reunião de fatos e métodos cujos pesquisadores, com sucesso ou não, empenham-se em contribuir com um ou outro elemento para essa constelação específica. $O$ desenvolvimento científico, torna-se processo gradativo, onde itens são adicionados isoladamente ou em combinação ao conhecimento. (idem,p.20).

Afinal o conteúdo axiológico, a eleição valorativa, é um dos aspectos essenciais da ciência. Como decorrência, o ponto de convergência poderia centrar-se em pesquisas multidisciplinares, sendo o eixo, o fio condutor, o enfoque nos valores contidos na genericidade.

Heller nos adverte que " "em uma primeira aproximação, a genericidade é idêntica à socialidade, porém a sociedade, a estrutura social de uma sociedade dada em uma época, não encarna (ou não encarna completamente) a genericidade, o desenvolvimento genérico. Assim pois será possível que um homem afirme o desenvolvimewnto genérico negando uma estrutura social dada' '. (Heller, 1977,p.33 - grifos no original).

Para cumprir-se tal finalidade, o principio da pluralidade é fundamental. Isto significa que incentiva-se a exteriorização para o diálogo, para o debate, para 0 confrontamento de conteúdos diferenciados que possam estar presente nos agentes históricos.

Esta assertiva consiste em apoiar todo o esforço teórico, sobre a dialética - das relações e processos universais, de sua produção sempre única - a fim de introduzir-se o rigor conceitual e de apreender-se as necessidades de desenvolvimento num dado momento histórico. Aqui, a divergência, a divisão, a pluralidade de idéias - longe de ser ecletismo - não se efetua mais entre generalidades que cristalizam num modelo toda a racionalidade abstrata, mas entre representaçð̃es teóricas dos processos geradores $\mathrm{e}$ apreensão judiciosa de um engendramento singular. 
Tampouco se pretende construir um modelo de sociedade geral, mas na verdade, propor a rede teórica de relaçðes e procedimentos através da qual é possível, por meio de um esforço sempre concreto, pensar racionalmente uma formação social idiossincrática como a nossa.

A retomada do cotidiano, exemplificada através das várias esferas heterogêneas que o compðem ${ }^{1}$, redimensiona e unifica atividades culturais e científicas. Esta visão faz-se muito mais abrangente e enriquecida, pois retoma o processo integral da vida dos sujeitos dando ênfase à interdependência dos aspectos da realidade social, globalmente considerada.

Claro está que a emancipação dos homens tem necessariamente uma dimensão cognitiva. O conhecimento produz "ao mesmo tempo um efeito de aceleraçăo e um efeito de apropriação (...) acelera a emancipação prática, e como apropriação, domínio teórico". Assumir o ponto de vista do conhecimento implica assumir também o ponto de vista da transformação. (Bertrand,1989, p.38).

Nosso enfoque centra-se no indivíduo, no conjunto das relaçðes sociais, no cotidiano, onde a tomada de consciência é fator decisivo. No interior da unidade dialética constituida pelas relaçð̃es sociais e pela formação social, nem antes, nem depois, o exercício para democracia dar-se-ia no durante, no processo.

É um caminho possivel que perpassa necessariamente pela compreensão das estruturas de sentimentos, de valores, de pensamentos, de usos e costumes, e mais, delimita o caminho das relaçðes no sistema geral da vida.

Nesta assertiva, a objetivação científica tende a ser reavaliada, na medida em que envolve representações cotidianas. Este é um entre outros pontos críticos.

Sabemos ${ }^{2}$ que a consciência é o momento pelo qual se ultrapassa a representação (significação) para chegar ao significado. Não se pode atingir a consciência sem a representação, e por outro lado, a consciência não existe sem a representação, que é uma forma tal como a democracia. É notório que toda forma de algum modo é ideologia, é uma anteposição, ideal, mental.

O ideológico explica a representação. A consciência explica a representação chegando a um significado. Nesta reflexão tanto a consciência como a representação são ideologias. A representação antecede. A consciência poscede. Mas, mesmo com essa inadequação interna, a consciência reificada não pode ser eliminada a não ser pela transformação prática das condiçð̃es objetivas que criaram.

A busca da adequação e autenticidade da consciência não se dá com o amor abstrato à verdade que difere de um pólo a outro da sociedade e, inevitavelmente seu destino é e será diferente.

1 Conceito teórico explicativo por Agnes Heller.

2 É preciso observar que esta reflexão encontra-se desenvolvida em tese de doutorado defendida em 1992, na Escola de Comunicações e Artes da Universidade de Săo Paulo, intitulada "O Individuo Representativo: Considerações Sobre as Relações entre Valores Individuais e Consciència Social".

Paidéia, FFCLRP-USP, Rib. Preto, 7, Agosto/1994. 
Se a consciência se dirige à negação de si, da própria vida, à impotência, a sua adequação implica a inadequação objetiva às relaçðes vitais e reais do homem. Reitera e reproduz a ideologia da classe dominante. Por outro lado, se a consciência se dirige à negação da negação de si, no pólo do saber crítico da consciência alienada, do trabalho, essa aspiração é verdadeiramente vital, pois não nega o conteúdo real da vida humana, não se contradiz, afirma o desenvolvimento coletivo dentro das condiçðes e possibilidades histórico-sociais.

Se entendermos a objetivação como conteúdo de qualquer atividade que envolve finalidades conscientes, então, essa in-serção conceitual ao processo de objetivação humana na ciência - levando-se em conta a significação orgânica do cotidiano, do senso comum - confrontar-se-iam multiplicidades de posiçð̃es, discursos, significados sócioculturais .

O cotidiano torna-se-ia um locus privilegiado e fertilizante de resistência científica e cultural contra o mundo desumanizado e desumanizante que caracteriza a sociedade hoje.

À nossa intenção para redefinir a prática democrática a partir do cotidiano subjaz a proposta de Heller : "a elevação da particularidade individual ao genericamente humano'. Nesta postura está implícito o cotidiano como mediaçðo para o exercício da democracia e a explicitação e prática de valores éticos que contribuam para o crescimento axiológico do ser social. (Helller, 1977,p.30-35).

Claro está que, para nós, a consciência reificada não coincide com o ser social em movimento. Há um hiato relativo entre a consciência e o ser social potencializado pela reificação.

Aqui, podemos recorrer a uma das contribuições gramscianas, especialmente o conceito de " intelectual orgânico". Afinal, são os intelectuais orgânicos, ou os operários de vanguarda das classes sociais os que constituem a sua consciência crítica, que só é possível através de um distanciamento de classe em relação a si mesma. (Gramsci,apud.Santos, 1980,p.51)

Assim, a prática científica, coerente e criteriosa transformar-se-ia em praxis cotidiana, que constitui a síntese entre a atividade prática dos indivíduos e o conhecimento. É a consciência, em diferentes níveis de elaboração, que orientaria e daria significação às atividades práticas desenvolvidas pelo indivíduo, isolada ou socialmente. Sistematizar os dados do cotidiano para captar, através de sucessivas aproximaçõcs a totalidade reificada, nada mais é do que exercer a praxis intencional ${ }^{3}$.

Não é o caso de propormos mais uma elite intelectual que detenha o poder. Uma elite que reorienta a massa pode ser perigosa. Trata-se de uma conversão por cada um,

3 A expressão aparece com Sánches Vázquez na obra Filosofia da Praxis. (Rio de Janeiro, 1968, p 317-372); foi resgatada por João E.Evangelista em: Crise do Marxismo e Irracionalismo PósModerno (Cortez, 1992). 
da aparição em cada um, de uma nova concepção de vida.

Em oposição ao individualismo que caracteriza a sociedade atual, modelo idílico da propriedade privada, em todos os niveis, a moral socialista proclama a importância decisiva dos interesses sociais; é o que na terminologia helleriana denomina-se individuum e "que se encontra em relação consciente com a genericidade e que ordena sua vida cotidiana com base também nessa relacăo consciente - evidentemente no seio das condiçőes e possibilidades dadas", isto é, quando conjugam-se valores éticos que expressam a essência humana.(Heller,1977,p.55)

As categorias marxianas constitutivas de essência humana que expressam os valores contidos na genericidade dizem respeito ao trabalho (objetivação), a socialidade (historicidade), à universalidade, a consciência e a liberdade. (cf.Markús, 1974, p.50-52).

Estes seriam, prioritariamente, os valores a serem retomados, no processo de ressocialização e nele a formação da identidade, isto é, a formação da identidade de um contexto autoritário controlador para um contexto democrático, exige um certo desenvolvimento temporal comum.

Parece-nos que a identidade de um povo é o resultado de forças que se contrapð̌em progressivamente, de situaçðes conflitivas específicas em que os indivíduos se fortalecem gradualmente no meio social através de identificaçðes. Seria na associação dialética de assimilação e intervenção, no processo, que se consubstanciaria a luta democrática.

Nesta prática há uma medular vinculação entre liquidação do capitalismo, democracia e transição socialista. Esta prática requer não só a crítica profunda dos equívocos do passado, teóricos e práticos, como ainda a clarificação do valor da democracia brasileira.

Esta proposta considera o homem e o mundo na sua relação de reciprocidade. No movimento supra-estrutural incluem-se a substância da sociedade, ou seja, suas finalidades e metas. Deste modo, nasceriam seus produtos identitários onde o desenvolvimento axiológico seria a eleição consciente de princípios válidos para todos.

As reflexð̃es múltiplas que estruturam as relaçð̃es sociais são mantidas pela atividade dos indivíduos, de tal forma que é lícito dizer-se que as identidades, no seu conjunto, refletem a estrutura social ao mesmo tempo que reagem sobre ela conservando-a ou transformando-a.

Assim, a identidade que se constitui no produto de um permanente processo de identificação, aparece como um dado e não como um dar-se constante que expressa o movimento sem a ausência da história.

Neste aspecto, a atividade humana tanto interna como externa, caracteriza-se pela atividade consciente. Quanto maior for a possibilidade que uma estrutura social dada oferece ao homem para atuar de forma livre, maior a possibilidade de transformála no predomínio da consciência para si. 
Mas de todo modo entendemos que a escolha consciente - e este é o sentido essencial do indivíduo - existe quanto mais consciente for sua escolha das açðes, orientadas para um determinado objetivo. A liberdade se obtém na medida de sua consciência dos objetivos e caminhos a aspirar pela açôes correspondentes. (Schaff, 1967,p.153-182).

Esta interpretação lembra que a escolha consciente é feita em virtude de um determinado sistema de valores, com o qual o indivíduo pode identificar-se ou com ele entrar em conflito, independentemente da escolha feita.

Para nós, o conflito é a rebelið̃o das sadias aspiraçð̃es humanas contra o conformismo. A possibilidade de liberdade do indivíduo, assim compreendida, está em contradição com a espontaneidade da evolução histórica e não com seu caráter objetivo.

Aqui delimitamos a concepcão da liberdade como necessidade reconhecida, pontos de partida e de chegada para algumas de nossas consideraçðes acerca da redefinição democrática, através da conscientização dos valores éticos exercitados pela praxis intencional, viabilizando nossas reflexðes.

\section{CONCLUINDO}

Por certo que nosso sistema dissocia, fragmenta e atomiza o ser particular, mas é importante verificar as maneiras pelas quais esse sistema, como qualquer outro, controla as idéias e representaçð̃es, contribuindo para formar as consciências daqueles que são seus defensores, como também daqueles que se revoltam contra ele.

Somos testemunhas e co-autores de um vigoroso movimento da sociedade na conquista e consolidação da democracia . É crível supor uma retomada da funcionalidade no interior deste processo. Questão fulcral, por outra parte, seria situar com precisão, a que tipo de ordenamento democrático se faz referência quando tematiza-se as exigências democráticas. Democracia-método ou democracia-condição social ? A proposta de redefinição a partir de matrizes clássicas, engloba uma dupla tarefa: a universalização da democracia-método e a sua superação na democracia-condição social a partir do cotidiano. Afinal, a vida cotidiana é a vida de todo homem. Este caminho constitui precisamente o tempo sócio-histórico em que, simultaneamente, se operaria o processo democrático.

Ressalta-se que esta ressocialização nãoé só um dos traços distintivos da projeção clássica; na apreciação das transformaçðes sociais do mundo contemporâneo ela adquire extraordinário relevo.

De fato, pode-se admitir que se está buscando evitar e minimizar a costumeira alienação dos participantes, principalmente das instituiçőes públicas - por forçar esta reificação advinda da divisão do trabalho especializado que se cristaliza nos chamados vieses burocráticos - ao mesmo tempo que se está buscando favorecer a concepção e o exercício da liberdade humana entendida como necessidade reconhecida. 
A liberdade humana significa a possibilidade de opção vinculada à responsabilidade. Responsabilidade que significa a valoração que 0 indivíduo vai dar à decisăo tomada, e que direção vai dar a ela. Segundo tal acepção a liberdade pressupore a responsabilidade que por sua vez é a condição da própria liberdade.

Assim, a atividade democrática exercida no cotidiano para ser representativa possui sempre uma finalidade, uma meta, um objetivo que decorre da possibilidade histórica determinada. É por isso que cada ato livre é simultaneamente um ato responsável. E esta responsabilidade cabe a todos nós. Nesta linha de argumentação o prever atos, guiar-se pelos interesses da maioria, pelo desenvolvimento da sociedade em geral e da comunidade em específico, na promulgação dos valores contidos na genericidade em detrimento do "eu", é uma entre outras proposta viáveis rumo à democratização.

Esta assertiva não se limita a dizer o que o homem é, mas procura elementos para responder ao que ele pode vir a ser, dentre as alternativas possíveis. A humanização sintetiza algumas categorias que apreendem a unidade do gênero humano: o trabalho consciente, delimitando-se finalidades e metas precisas de atuação.

É preciso lembrar que nos "Grundrisse", Marx atenta para o fato que os indivíduos se encontram diante de uma realidade que eles não dominam, da qual não conhecem as leis ou as conhecem apenas de modo incompleto; e portanto, diante de uma totalidade que se encontra objetivamente fora deles e que não conseguem subsumir internamente na própria consciência; e na "6a. Tese sobre Feuerbach" esclarece que a essencia humana não é uma abstração inerente ao individuo singular. Em sua realidade é o conjunto das relaçð̌es sociais.(Marx,apud Siveira,1989,p. 41- 76).

Logo, não há identidade entre totalidade sócio-histórica e totalidade da consciência. $O$ que existe é a possibilidade, é o esforço continuado do exercício da praxis intencional.A combinaçăo de praxis intencionais particulares integram-se numa prática coletiva. Não nos esqueçamos que a reificaçăo também é contraditória: coexistem a apatia e a inquietude e portanto a possibilidade do salto 4 .

Salienta-se que esta postura é apenas uma entre outros caminhos possiveis para se fazer pensar e redefinir a democracia, por várias áreas do conhecimento e por vários canais de que tanto clama, e carece a sociedade.

Os parâmetros democráticos não se esgotam no conjunto do sistema em que se vive. A democracia situada no patamar de uma participação social com base no cotidiano é uma proposta que, sem dúvidas, poderá ser alargada e exercitada em todos os níveis.

Afinal ter consciência do objetivo pelo qual se vive, também é uma necessidade humana. A perda dessa consciência, constitui o fundamento das diferentes enfermidades psíquicas. É sob as diretrizes de pluralidade e descentralização que pode-se admitir

4 Categoria Lukácsiana.

Paidéia, FFCLRP-USP, Rib. Preto, 7, Agosto/1994. 
que o atual momento configura-se como um acrescentamento à qualidade que já a caracterizava.

Mesmo assim, só a prática histórica referendará ou não esta proposta.

\section{REFERÊNCIAS BIBLIOGRÁFICAS}

BERTRAND,M. "O Homem clivado- a crença e o imaginário".In. Elementos para uma Teoria Marxista da Subjetividade. Paulo Silveira e Bernard Doray (org), 1989.

CHAUÍ,M. Cultura e Democracia.São Paulo, Cortez, 4a.ed.,1989.

COUTINHO,C.N. Gramsci. Porto Alegre,L\&P, 1981.

GONZÁLEZ,F. Psicologia de la Personalidad. La Habana,Puebloy Educacíon, 1985.

GRAMSCI,A. Concepção Dialética da História.Rio de Janeiro, Civilização Brasileira,2a.ed., 1978.

HELLER,A. O Quotidiano e a História.Rio de Janeiro.Paz e Terra, 1972.

Sociologia de la Vida Cotidiana. Barcelona, Península, 1977.

KUHN,T.S. A Estrutura das Revoluções Científicas.São Paulo, Perspectiva, 1990 MARKÚS,G. Marxismo y Antropologia.Barcelona,Grijalbo,1974.

MARX,K. Le 18 Brumaire de Louis Bonaparte. Paris,Éditions sociales, 1984.

“'A relação da propriedade privada"'(Segundo Manuscrito). Manuscritos Económicos - Filosóficos. México, Editorial Grijalbo, 1968.

NĖTTO,J.P. Democracia e Transição Socialista.Belo Horizonte, Oficina de Livros, 1990.

SANTOS,J.A.A. "Gramsci: ideologia,intelectuais orgânicos e hegemonia”.In : GRAMSCI,A., TOGLIATTI,P., LABASTIDA,J. Temas de Ciências Humanas, 1980.

SCHAFF,A. O Marxismo e o Indivíduo. Rio de Janeiro, Civilização Brasileira, 1967.

SILVEIRA, et alli. Elementos para uma Tcoria Marxista da Subjetividade. São Paulo, Vértice. 


\section{ABSTRAT}

Searching to reafirm the importance of Marxist theory, this papaer proposes the redefinition of democracy as a method and the possibility of its overcome to democracysocial conditions through intentional rule daily acted. The comprehension of the quotidian life, requires its ontological reconstitution by the consciousness of the ethical values inclued in the humankind.

Key Words: marxist theory and democracy; consciousnes and ethical values; quotidian and intentional rule.

Palavras-Chave: teoria marxista e democracia; conscientização e valores éticos; cotidiano e praxis intencional. 
